\title{
Surgical Rescue in a High-volume Urban Emergency General Surgery Service at a Middle-income Country
}

\author{
Maria F Jimenez ${ }^{1}$, Andrés Isaza-Restrepo ${ }^{2}$, Danny Conde ${ }^{3}$, Alex Arroyo ${ }^{4}$, Milcíades Ibánez-Pinilla ${ }^{5}$, Felipe Borda ${ }^{6}$, \\ Daniel Colmenares ${ }^{7}$, Juan C Puyana ${ }^{8}$
}

\begin{abstract}
Introduction: The capacity for prompt "rescue" from death in patients with complications has become an important marker of the quality of care since mortality and morbidity have been identified as incongruous indicators. This study aims to describe the incidence of "surgical rescue" failure and the outcomes of emergency general surgery (EGS) patients at a large academic medical center.

Materials and methods: In our high-volume surgical hospital, an electronic EGS registry was developed to automatically capture in-hospital information and outcomes from the Electronic Medical Record (EMR). Surgical complications were included in an online application and automatically captured in the electronic EGS registry, and prospectively screened from June to July 2017 for acute EGS surgical patients from operative procedures.

Results: A total of 501 patients (average age: $53.9 \pm 20.9,56.5 \%$ female) underwent 882 EGS procedures. Thirteen patients (2.6\%) of the 501 patients required "surgical rescue", mainly for uncontrolled sepsis (43\%) and anastomotic leakage (30\%). The surgical rescue failure rate (inability to prevent death after a surgical complication) was $15.4 \%$. Patients requiring critical care (OR = 3.3, IC 95\%: 1.04 , 10.5), hospital admission $(p=0.038)$, and hospital LOS (days) $(p=0.004)$ were significantly higher for the surgical rescue patients than for those without complications. Conclusion: Surgical failure to rescue rate was similar among high-volume EGS services, as has recently been described in the United States. The latest development and implementation of an electronic automatic captured EGS registry database in our academic medical center will serve to build best practices for "surgical rescue" and drive quality improvement programs.

Keywords: Electronic registry, General emergency surgery, Surgical rescue.

Panamerican Journal of Trauma, Critical Care \& Emergency Surgery (2021): 10.5005/jp-journals-10030-1305
\end{abstract}

\section{INTRODUCTION}

Recent evidence demonstrates that complications across surgical specialties in the United States do not differ from high- to lowvolume hospitals. However, mortality varies according to the speed and proper measures from acute surgical care to the "rescue" of patients with complications, such as death. Failure to "rescue" these patients with complications has been recently regarded as an important indicator of patient safety and quality of care. ${ }^{1-6}$ Subsequently, hospitals can be divided in terms of quality, into high-performing and low-performing hospitals according to their capacity to surgically rescue patients from complications.

In our high-volume emergency general surgery (EGS) academic service ( 805 beds) in a middle-income country, an automatic electronic EGS registry was developed for quality control to automatically capture in-hospital information and outcomes from the Electronic Medical Record (EMR) since there is no option to buy commercial acute care registries or hire registrars to capture databases.

The primary aim of this study is to describe the incidence of surgical rescue failure, defined as the inability to prevent death in emergency surgical patients with complications, in our academic healthcare center. Our secondary objectives were to define the quality of care of EGS cases through the electronic automatic EGS registry in our institution and to compare quality indicators from our service against international standards.

\section{Materials and Methods}

\section{Sources of Information}

A prospective electronic captured EGS registry including data on demographics, primary EGS coding, severity, surgical procedures,
${ }^{1-3}$ Department of Surgery, General Surgeon-Hospital Universitario Mayor, Universidad del Rosario, Bogota, Colombia

${ }^{4}$ Department of Surgery, Statistics Hospital Universitario Mayor, Bogota, Colombia

${ }^{5}$ Department of Surgery, Epidemiology Hospital Universitario Mayor, Bogota, Colombia

6,7 Department of Surgery, PGY-5 Hospital Universitario Mayor, Bogota, Colombia

${ }^{8}$ Department of Surgery, University of Pittsburgh, Pennsylvania, USA

Corresponding Author: Maria F Jimenez, Department of Surgery, General Surgeon-Hospital Universitario Mayor, Universidad del Rosario, Bogota Colombia, Phone: +57 320492 8466, e-mail: mafejimenez2000@gmail.com

How to cite this article: Jimenez MF, Isaza-Restrepo A, Conde D, et al. Surgical Rescue in a High-volume Urban Emergency General Surgery Service at a Middle-income Country. Panam J Trauma Crit Care Emerg Surg 2021;10(1):16-19.

Source of support: Nil

Conflict of interest: None

and 30-day postoperative outcomes was developed by extracting into an Excel database the de-identified information included in the hospital EMRs of patients undergoing EGS procedures in an urban academic medical institution in Bogota, Colombia, during June and July 2017. Inclusion criteria were adult patients ( $>16$ years) undergoing emergency surgical procedures during the study period. Patients undergoing trauma surgical procedures were excluded. Only complications requiring surgical procedures in the operating room in adult patients ( $>16$ years) undergoing

(c) The Author(s). 2021 Open Access This article is distributed under the terms of the Creative Commons Attribution 4.0 International License (https:// creativecommons.org/licenses/by-nc/4.0/), which permits unrestricted use, distribution, and non-commercial reproduction in any medium, provided you give appropriate credit to the original author(s) and the source, provide a link to the Creative Commons license, and indicate if changes were made. The Creative Commons Public Domain Dedication waiver (http://creativecommons.org/publicdomain/zero/1.0/) applies to the data made available in this article, unless otherwise stated. 
nontraumatic general emergency surgical (EGS) procedures during June and July 2017 were included. Perioperative medical complications, such as ventilator-associated pneumonia, septic shock, acute renal failure, acute myocardial infarction, and catheterrelated urinary tract infection, were not included.

The emergency general surgeons identified 24 hours a day prospective surgical complication and were immediately included and classified them according to Clavien-Dindo in an online application specifically developed for this purpose. During morning rounds, investigators identified and included complications that may not have been included in the previous 24 hours. This information was also automatically captured in the electronic EGS registry. Surgical chart reviewers of patients with complications confirmed the quality assurance of the captured data. Only surgical complications requiring surgical procedures in the operating room were included.

\section{Identification of Complications and Interventions}

The database of the EGS service was screened for 30-day mortality and complications for any surgical procedure that was not related to trauma. Surgical chart reviewers categorized the complications as anastomotic dehiscence/leak, wound dehiscence, perforated viscera, biliary tract injury, and organ/space surgical site infection. Interventions were classified as biliary repair/reconstruction, bowel resection, hernia repair, hemorrhage control, source control infection, wound debridement, laparostomy, and/or hemicolectomy. Medical complications, such as renal failure, myocardial infarction, ventilator-associated pneumonia, acute renal failure, and septic shock, were not included.

The time to surgery was calculated from the time when the surgical decision was made until the surgical incision was performed according to the EMR for all the EGS surgical procedures.

\section{Statistical Analysis}

The data were processed by the authors with the statistical software SPSS version 20.0. Descriptive measures were described as the mean \pm standard deviation or median (interquartile range). To identify the association between the clinical variables and complications, the Chi-square test or Fisher's exact test was employed as appropriate. The normality of the quantitative variables was evaluated with the Kolmogorov-Smirnov and Shapiro-Wilk tests. The differences between the averages with Student's $t$-test were determined for two independent groups with homogeneous or heterogeneous variances. This assumption was previously evaluated with the Levene test, and in the case of distributions other than normal, the nonparametric asymptotic Wilcoxon-Mann-Whitney test was used. Values of $\alpha<0.05$ were considered statistically significant $(p<0.005)$.

\section{Institutional Review Board and the Ethics Committee Approval}

The Institutional Review Board and the Ethics Committee at the Hospital Universitario MEDERI approved this study. Patient consent was not obtained because the data used are part of the standard processes of care and were extracted without identifying data in our electronic EGS registry.

\section{Results}

Of 962 emergency surgical procedures performed at the Hospital Universitario Mayor-Mederi in Bogota, Colombia, during June and July 2017, 91.7\% $(n=882)$ corresponded to EGS in 501 patients.
The mean age of these EGS patients was $53.9 \pm 20.9$ years, and $56.5 \%$ were female. Table 1 presents the distribution and time to surgery of the initial top 10 EGS procedures performed.

Of these 501 patients, 2.6\% ( $n=13)$ presented with an EGS surgical complication, confirmed by the medical record. The overall EGS mortality was $6.7 \%(n=33): 1.0 \%(n=5)$ within 24 hours, $0.2 \%$ $(n=1)$ between 25 and 48 hours, and $5.4 \%(n=27) 48$ hours after admission.

The surgical rescue failure rate, which was defined as the inability to prevent death after a surgical complication, was $2 / 13$ (15.4\%).

The most common complications requiring surgical rescue interventions in the operating room $(2.6 \%, n=13)$ were anastomotic leakage $(38.5 \%, n=5)$, uncontrolled sepsis $(30.8 \%, n=4)$, and hemorrhage $(30.8 \%, n=4)$. The surgical rescue interventions performed were source control of infection $(38.5 \%, n=5)$, hemorrhage control $(30.8 \%, n=4)$, bowel resection $(23.1 \%, n=3)$, and wound debridement $(7.7 \%, n=1)$. The cause of non-planned surgical intervention for the two patients we failed to rescue was an anastomotic leak.

The median time of surgery for all rescue patients was 5.1 hours. Table 2 depicts the time to surgery for the surgical rescue patients according to mortality.

In terms of outcomes, the surgical rescue patients were significantly more prone to be admitted to the hospital and have a longer hospital length of stay than the non-rescue patients. Table 3 shows the outcomes of the EGS patients with surgical complications.

\section{Discussion}

The collection of reliable data and outcomes to support surgical quality improvement programs in low- and middle-income countries (LMICs) has become one of the top public health priorities. ${ }^{7,8}$ We described here the surgical failure to rescue rate (15.4\%), overall 30 -day mortality (6.7\%), and complications requiring surgical rescue interventions (2.6\%) in the largest academic medical institution in Colombia over 2 months. All our surgical rescue procedures were solved in the operating room. The most common causes for surgical rescue in our cohort were anastomotic leakage (38.5\%), uncontrolled sepsis (30.8\%), and hemorrhage (30.8\%). The surgical rescue interventions were source control of infection (38.5\%), hemorrhage control (30.8\%), bowel resection (23.1\%), and wound debridement (7.7\%). The cause of non-planned surgical intervention for the two patients we failed to rescue (15.4\%) was an anastomotic leak. Surgical rescue patients had significantly higher admission rates to the hospital than non-rescue patients [100\% ( $n=13)$ vs $77.5 \%, p<0.05]$ and had a longer hospital length of stay $[22.7 \pm 24.9(n=10)$ vs $11.2 \pm 14.3, p<0.01]$. Admission to the ICU (30.8 vs $11.9 \%)$, need for mechanical ventilation (15.4 vs $8.4 \%)$, and in-hospital mortality (15.4 vs $6.6 \%$ ) were also higher in the surgical rescue group than in the nonrescue group but did not reach statistical significance.

Recent publications in the US have demonstrated that EGS patients are 8 times more prone to die after surgery, present $50 \%$ more postoperative complications, and have a $14 \%$ more likely to be readmitted than patients undergoing the same surgical procedure electively. ${ }^{9,10}$ The EGS diagnosis represents almost 7\% of all hospital admissions in the US, embodying a yearly cost of more than $\$ 28$ billion. ${ }^{11}$ Unfortunately, in Colombia, the burden of disease of EGS patients has not yet been estimated. From a previous (2013) nonpublished research paper by the authors in our 
Surgical Rescue in a High-volume Urban EGS Service at a Middle-income Country

Table 1: Distribution and time to surgery of the top 10 emergency general surgery surgical procedures

\begin{tabular}{|c|c|c|c|c|c|}
\hline Surgical procedure & $N$ & $\%$ & Media hours & Deviation & Median hours \\
\hline Laparoscopic cholecystectomy & 149 & 16.9 & 19.119 & 13.5951 & 17.300 \\
\hline Appendectomy (open) & 97 & 11.0 & 5.141 & 3.9804 & 4.100 \\
\hline Peritoneal lavage (open) & 75 & 8.5 & 12.391 & 8.9310 & 12.600 \\
\hline Laparoscopic exploration & 46 & 5.2 & 6.817 & 5.3172 & 5.200 \\
\hline Lyses of adhesions for intestinal obstruction (open) & 29 & 3.3 & 11.314 & 11.2008 & 6.800 \\
\hline Abdominal exploration & 16 & 1.8 & 6.831 & 5.7902 & 6.050 \\
\hline Drainage intra-abdominal collection (open) & 15 & 1.7 & 7.467 & 5.5695 & 6.500 \\
\hline Hernia-ventral/umbilical/ & 12 & 1.4 & 9.750 & 6.6028 & 8.400 \\
\hline Partial omentectomy (open) & 11 & 1.2 & 6.791 & 5.3665 & 6.000 \\
\hline $\begin{array}{l}\text { Postoperative abdominal closure due for abdominal } \\
\text { wound dehiscence }\end{array}$ & 10 & 1.1 & 15.920 & 7.1622 & 17.300 \\
\hline
\end{tabular}

Table 2: Time to surgery for surgical rescue patients

\begin{tabular}{|c|c|c|c|c|c|c|}
\hline Mortality & Media & Deviation & Median & Min & Max & $N$ \\
\hline Yes & 2.150 & 0.0707 & 2.150 & 2.1 & 2.2 & 2 \\
\hline No & 11.673 & 11.9655 & $5.200^{*}$ & 2.3 & 43.5 & 11 \\
\hline Total & 10.208 & 11.4935 & 5.100 & 2.1 & 43.5 & 13 \\
\hline
\end{tabular}

${ }^{*} p=0.013$, Wilcoxon-Mann-Whitney exact test

Table 3: Outcomes of emergency general surgery patients with surgical complications

\begin{tabular}{|c|c|c|c|}
\hline Surgical complication? & Yes $(n=13)$ & No $(n=488)$ & $p$ \\
\hline Critical care & $30.8 \%(n=4)$ & $11.9 \%(n=58)$ & $0.064^{*}$ \\
\hline Hospital admission & $100 \%(n=13)$ & $77.5 \%(n=378)$ & $0.038^{*}$ \\
\hline Hospital LOS (days) & $\begin{array}{l}22.7 \pm 24.9 \\
(\operatorname{med}=10.0)\end{array}$ & $\begin{array}{l}11.2 \pm 14.3 \\
(\mathrm{med}=6.0)\end{array}$ & $0.004^{* *}$ \\
\hline $\begin{array}{l}\text { ICU length of stay } \\
\text { (days) }\end{array}$ & $\begin{array}{l}8.3 \pm 7.9 \\
(\mathrm{med}=5.0)\end{array}$ & $\begin{array}{l}12.8 \pm 14.4 \\
(\text { med }=6.0)\end{array}$ & $0.441^{* *}$ \\
\hline Mechanical ventilation & $15.4 \%$ & $8.4 \%$ & 0.309 \\
\hline In-hospital mortality & $15.4 \%$ & $6.6 \%$ & 0.596 \\
\hline
\end{tabular}

Data are presented as med $=$ median or percentage. $p$ values calculated by *Fisher's exact testing or ${ }^{* *}$ Wilcoxon-Mann-Whitney

institution, we proposed a registry for the quality follow-up of EGS patients to describe the quality of care in acute care surgery patients and compare our performance with the international standard of care. From this retrospective review of the clinical records of 231 EGS consecutive patients over a month, the 30-day postoperative mortality was $3.46 \%$, the severe complication rate was $8.04 \%$, the in-hospital stay length was 6.54 days \pm 5.18 , and the intensive care unit stay length was 5.7 days \pm 4.42 , similar to the outcomes described by Ingraham et al. ${ }^{12,13}$

Hospital Universitario Mayor is the largest healthcare institution in Colombia with a high surgical volume. Despite having only one operating room devoted to emergency procedures for all specialties, EGS operations were promptly performed according to national and international standards. The median time to surgery was 4.1 hours for appendectomy, 6.0 hours for abdominal exploration, and 17.3 hours for laparoscopic cholecystectomy. Our surgically rescued patients also underwent prompt intervention (median 5.1 hours). Additionally, surgical rescue failure patients (patients with complications who died) were significantly more promptly operated on than the surgical rescue patients who survived ( 2.15 vs 5.20 hours, $p=0.013$ ), indicating our readiness to intervene in the more defiant cases.

"Failure to rescue" has become an important marker of quality of care, since mortality and morbidity have been identified as incongruous markers, and the variance in mortality is derived from the capacity of prompt and successful "rescue" of surgical patients from complications. Our failure to rescue rate in our EGS cohort was similar to that described in recent publications. ${ }^{14-16}$ Our data correspond to a prospective study of surgical complications, different from most of the literature where records come from retrospective administrative registries, with less capacity to detect all the complications. ${ }^{15}$ As previously described by Kutcher et al., ${ }^{16}$ the hospital admission and hospital stay of surgical rescue patients were significantly higher than those of the non-surgical rescue group. The plausible explanation for not reaching a significant difference for outcomes, such as admission to the ICU, need for mechanical ventilation and in-hospital mortality between the complicated cases vs non-complicated cases is the small size of our cohort.

\section{Benefits}

The benefits of acute care registries have been extensively described. ${ }^{17,18}$ However, collecting data to improve the efficiency and quality of care can be particularly challenging in LMICs. ${ }^{19-21}$ Financial limitations, lack of well-trained health registrars, and an increase in the already substantial burden of healthcare providers reduce the possibilities of their implementation. ${ }^{21}$ In our setting, it is not possible to buy a commercial registry or to hire trained registrars to capture data for our EGS registry. To overcome these limitations, we developed an application for the clinician to daily include and Clavien-Dindo classify complications in our patients. Additionally, an electronic EGS registry was developed to automatically capture in-hospital information and outcomes from the EMR. We overcame the need for paper or extra portable computers for data extraction and entry. As previously demonstrated, electronic health registries 
can be more efficient and cost-effective than paper-based registries. ${ }^{20,22}$

Our study has several limitations. Biases of a single institution may not represent the epidemiology of surgical rescue failure at other institutions. Determination of patient severity is necessary for making meaningful comparisons between the performance of providers and institutions. ${ }^{23}$ Patient risk factors contribute to outcomes, such as mortality and morbidity. Risk adjustment is the statistical method for accounting for the differences in patient case mixtures, such as EGS patients, that impact care outcomes. ${ }^{24}$ A risk-adjustment analysis of our cohort could not be performed since data, such as the American Society of Anesthesiologists (ASA) classification and comorbidities, were not parametric information in our hospital medical records. Therefore, these data could not be automatically captured, making it impossible to calculate risk adjustment.

\section{Conclusion}

The surgical failure to rescue rate (15\%) in our institution was similar to the rate recently described in comparable high-volume EGS services in the US. Surgical rescue patients more commonly required critical care and mechanical ventilation, longer hospital and ICU length of stay, and were less likely to be discharged to home than patients without complications. The in-hospital mortality rate was also higher in surgical rescue patients than in non-rescue patients. The development and implementation of an electronic automatic captured EGS registry database in our academic medical center serves to build best practices for "surgical rescue" and to drive quality improvement programs.

We have created at our institution an affordable system to monitor the quality of care in EGS that helps to plan hospital resources and define surgical quality improvement programs. The development and implementation of an electronic automatic captured EGS registry database in our academic medical center serves to build best practices for "surgical rescue" and to drive quality improvement programs.

\section{References}

1. Ghaferi AA, Birkmeyer JD, Dimick JB. Complications, failure to rescue, and mortality with major inpatient surgery in medicare patients. Ann Surg 2009;250(6):1029-1034. DOI: 10.1097/SLA.0b013e3181bef697.

2. Ghaferi AA, Birkmeyer JD, Dimick JB. Hospital volume and failure to rescue with high-risk surgery. Med Care 2011;49(12):1076-1081. DOI: 10.1097/MLR.0b013e3182329b97.

3. Ogola GO, Crandall ML, Shafi S. Variations in outcomes of emergency general surgery patients across hospitals: a call to establish emergency general surgery quality improvement program. J Trauma Acute Care Surg 2018;84(2):280-286. DOI: 10.1097/ TA.0000000000001755.

4. Almoudaris AM, Burns EM, Mamidanna R, et al. Value of failure to rescue as a marker of the standard of care following reoperation for complications after colorectal resection. Br J Surg 2011;98(12):17751783. DOI: 10.1002/bjs.7648.

5. Ferraris VA, Bolanos M, Martin JT, et al. Identification of patients with postoperative complications who are at risk for failure to rescue. JAMA Surg 2014;149(11):1103-1108. DOI: 10.1001/jamasurg.2014.1338.

6. Taenzer AH, Pyke JB, McGrath SP. A review of current and emerging approaches to address failure-to-rescue. Anesthesiology 2011;115(2):421-431. DOI: 10.1097/ALN.0b013e318219d633.
7. WHO. Sixty-eighth world health assembly WHA68.15 26 May 2015. https://apps.who.int > ebwha > pdf_files > wha68 > a68_r15-en.

8. Meara JG, Leather AJM, Hagander L, et al. Global surgery 2030: evidence and solutions for achieving health, welfare, and economic development. Lancet 2015;386(9993):569-624. DOI: 10.1016/S01406736(15)60160-X.

9. Lyu HG, Najjar P, Havens JM. Past, present, and future of emergency general surgery in the USA. Acute Med Surg 2018;5(2):119-122. DOI: 10.1002/ams2.327.

10. Kwan TL, Lai F, Lam CM, et al. Population-based information on emergency colorectal surgery and evaluation on effect of operative volume on mortality. World J Surg 2008;32(9):2077-2082. DOI: 10.1007/s00268-008-9632-7.

11. Ogola GO, Shafi S. Cost of specific emergency general surgery diseases and factors associated with high-cost patients. J Trauma Acute Care Surg 2016;80(2):265-271. DOI: 10.1097/TA.0000000000000911.

12. Ingraham AM, Haas B, Cohen ME, et al. Comparison of hospital performance in trauma vs emergency and elective general surgery: implications for acute care surgery quality improvement. Arch Surg 2012;147(7):591-598. DOI: 10.1001/archsurg.2012.71.

13. Ingraham AM, Cohen ME, Bilimoria KY, et al. Comparison of 30-day outcomes after emergency general surgery procedures: potential for targeted improvement. Surgery 2010;148(2):217-238. DOI: 10.1016/j. surg.2010.05.009.

14. Mehta A, Varma S, Efron DT, et al. Emergency general surgery in geriatric patients: how should we evaluate hospital experience? J Trauma Acute Care Surg 2019;86(2):189-195. DOI: 10.1097/ TA.0000000000002142.

15. Metcalfe D, Castillo-Angeles $M$, Olufajo OA, et al. Failure to rescue and disparities in emergency general surgery. J Surg Res 2018;231:62-68. DOI: 10.1016/j.jss.2018.04.047.

16. Kutcher ME, Sperry JL, Rosengart MR, et al. Surgical rescue: the next pillar of acute care surgery. J Trauma Acute Care Surg 2017;82(2):280286. DOI: 10.1097/TA.0000000000001312.

17. Shafi $S$, Nathens $A B, C r y e r ~ H G$, et al. The trauma quality improvement program of the American college of surgeons committee on trauma. J Am Coll Surg 2009;209(4):521-530.e521. DOI: 10.1016/j. jamcollsurg.2009.07.001.

18. Khuri SF, Daley J, Henderson W, et al. Risk adjustment of the postoperative mortality rate for the comparative assessment of the quality of surgical care: results of the national veterans affairs surgical risk study. J Am Coll Surg 1997;185(4):315-327. DOI: 10.1016/ S1072-7515(97)00073-2.

19. Paradis T, St-Louis E, Landry T, et al. Strategies for successful trauma registry implementation in low- and middle-income countriesprotocol for a systematic review. Syst Rev 2018;7(1):33. DOI: 10.1186/ s13643-018-0700-2.

20. Laing GL, Bruce $J \mathrm{~L}$, Aldous $\mathrm{C}$, et al. The design, construction and implementation of a computerised trauma registry in a developing South African metropolitan trauma service. Injury 2014;45(1):3-8. DOI: 10.1016/j.injury.2013.05.013.

21. Ankomah J, Stewart BT, Oppong-Nketia V, et al. Strategic assessment of the availability of pediatric trauma care equipment, technology and supplies in Ghana. J Pediatr Surg 2015;50(11):1922-1927. DOI: 10.1016/j.jpedsurg.2015.03.047.

22. Zargaran E, Spence R, Adolph L, et al. Association between real-time electronic injury surveillance applications and clinical documentation and data acquisition in a South African trauma center. JAMA Surg 2018;153(5):e180087. DOI: 10.1001/jamasurg.2018.0087.

23. Dimick JB, Osborne NH, Hall BL, et al. Risk adjustment for comparing hospital quality with surgery: how many variables are needed? J Am Coll Surg 2010;210(4):503-508. DOI: 10.1016/j.jamcollsurg.2010. 01.018.

24. Lane-Fall MB, Neuman MD. Outcomes measures and risk adjustment. Int Anesthesiol Clin 2013;51(4). DOI: 10.1097/AIA.0b013e3182a70a52. 